Article

\title{
Real Option Valuation of the R\&D Investment in Renewable Energy Considering the Effects of the Carbon Emission Trading Market: A Korean Case ${ }^{\dagger}$
}

\author{
Kyung-Taek Kim ${ }^{1}$, Deok-Joo Lee ${ }^{2, *}$ and Donghyun An ${ }^{2}$ \\ R\&D Strategy Division, Korea Institute of Energy Research, Daejeon 34129, Korea; ktkim@kier.re.kr \\ Department of Industrial Engineering, Seoul National University, Seoul 08826, Korea; dha214@snu.ac.kr \\ * Correspondence: leedj@snu.ac.kr \\ + This paper is an extended version of the paper "Economic Evaluation of Renewable Energy R\&D in the \\ Presence of Carbon Emission Market: Real Option Approach" presented to the Proceedings of the World \\ Congress on Engineering and Computer Science 2016 Vol II WCECS 2016, San Francisco, USA, 19-21 \\ October 2016.
}

Received: 15 November 2019; Accepted: 30 January 2020; Published: 1 February 2020

\begin{abstract}
A carbon market was introduced for the first time in January 2005, when the EU assigned carbon emission allowances to approximately 15,000 enterprises in 25 countries and established a market for emissions trading. In Korea, the carbon emission trading system started from January 2015 with three phases running up to 2025. As many countries have introduced carbon markets, new evaluation models that consider not only fossil energy prices but also carbon emission costs are necessary because additional costs of using fossil energy might have been incurred due to carbon emissions. The purpose of this paper is to develop a real option model that considers not only the uncertainty of existing fossil energy prices, but also the uncertainty of carbon emission rights prices, in evaluating the economic value of renewable energy R\&D. Using the real option model, we attempted to assess the effects of the uncertainty of newly appearing carbon markets on the economic value of renewable energy $R \& D$ in Korea empirically. Furthermore, we derived an optimal decision path according to the uncertain future situations of fossil energy and carbon markets by analyzing a trinomial lattice model in which the optimal timings of R\&D and deployment are identified.
\end{abstract}

Keywords: carbon emission market; renewable energy; economic evaluation; R\&D investment; real options

\section{Introduction}

As recognition that greenhouse gas emissions should be restricted to suppress global warming spread, the United Nations Framework Convention on Climate Change was signed during the United Nations Conference on Environment and Development in 1992. Five years after that, the Kyoto Protocol was adopted, which specified the quantity and the methods of reductions for each country obliged to reduce their greenhouse gas emissions in light of the United Nations Framework Convention on Climate Change. In addition, the Kyoto Mechanism was introduced such that the countries could smoothly perform their obligations. In the Kyoto Mechanism, carbon emission rights are treated as an intangible asset with property values, which can be traded based on the prices determined by supply and demand in carbon markets. A carbon market was introduced for the first time in January 2005, when the EU assigned carbon emission allowances to approximately 15,000 enterprises in 25 countries and established a market for emissions trading. Many countries, including the US, China, South Korea, and countries in the EU, are currently operating carbon markets. In Korea, the carbon emission trading system started from January 2015 with three phases running up to 2025. Korea remains on course 
to meet its target of a 30\% cut (233 MtCO2e) in greenhouse gas emissions by 2020 and the Korean Ministry of Environment published the new National GHG Emissions Reduction Roadmap 2020 in early 2014 [1].

Some important changes that occurred after major countries introduced carbon emissions trading systems include the stimulation of the development of carbon reduction technologies and the activation of the renewable energy sector. These changes indicate that carbon emissions trading systems are highly interrelated to renewable energy. In fact, the EU is operating financial support programs for member countries' low-carbon and renewable energy projects with revenues from the pre-allocated sale of carbon emission rights through the New Entrants Reserve (NER) 300 program. That is, the EU has established a link to virtuous circles of regulations and investments to ensure that the revenues from the trading of carbon emissions rights are invested in the development of low-carbon technologies and the growth of renewable energy sector. In particular, this system has spurred the development of low-carbon technologies for electric power generation companies since the energy sector is a major carbon emission source.

Developed nations have established long-term policies for renewable energy to cope with the emerging new era of energy after fossil fuel age. The amount of global investments in renewable energy increased from 40 billion dollars in 2004 to 214 billion dollars in 2013 [2]. South Korea has also recognized the importance of renewable energy, and has established long-term policies and made active investments in the renewable energy area. According to the 'New \& Renewable Energy 2014 White Paper' published by the New \& Renewable Energy Center of the Korea Energy Management Corporation (KEMCO), South Korea invested a total of 3714.5 billion KRW in R\&D in the renewable energy area from 1988 to 2013, of which the government invested 52.3\% (1943 billion KRW) and the private sector invested $47.7 \%$ (1771.5 billion KRW) [3].

An issue accompanies large investments in renewable energy is whether or not they are economically viable. To solve this problem, the EGEAS (Electric Generation Expansion Analysis System) model, which uses an optimization model of dynamic programming, was developed for generation planning and has evolved to advance the demand-side management and economic dispatch under deregulated environments. Therefore, it is known that the EAGAS model makes it possible to obtain an optimal operating plan under complex and various conditions such as probabilistic production cost [4]. In particular, some studies attempted to obtain optimal operating plans with the objective of minimizing costs or maximizing the contribution of renewable energy source using the EGEAS [5-8]. On the other hand, the real option model has developed to evaluate the economic values of investment in real assets and make a strategic decision making whether to invest or not considering uncertain environment, and many studies have been conducted using real option methodologies that are appropriate for deriving economic value or optimal strategic decision path of RE R\&D investment considering effects of uncertainties [9-11].

So far, studies that have used the real option approach to assess the economic value of renewable energy have mainly considered the uncertainty of fossil energy prices [12-19], because renewable energy and fossil energy can be regarded as substitute goods. Davis \& Owens [12] estimated the value of renewable energy generation technologies using a continuous real option model considering the price uncertainty of fossil fuels. Siddiqui et al. [13] assessed the economic value of renewable electric power R\&D programs using a binomial option-pricing model and compared their results with those obtained by Davis and Owens [12]. Jang et al. [15] evaluated the economic value of renewable energy R\&D through a real option method which considers not only the uncertainty of fossil energy prices but also the uncertainty of R\&D success. Kim et al. [16] performed an empirical analysis for measuring the economic value of the investment in wind power energy R\&D in Korea and optimal deployment timing of wind power technology by using the real option approach in which a compound option to abandon, deployment, or continue the R\&D was considered. Muñoz et al. [17] developed a decision-making model for wind energy investments taking into consideration the uncertainty of wind production and electricity prices based on real option analysis to specifically determine the probabilities one should 
invest, wait, or abandon a given project. Furthermore, Martinez-Cesena and Mutale [19] proposed a more advanced real option method in combination with optimization model for the evaluation of planning for renewable energy projects.

In addition to the uncertainty of fossil fuel energy prices, some recent studies have suggested that the factors regarding carbon market should be considered in the evaluations of the economic value of energy technologies including renewable energy, and have made efforts to reflect this factor. Kiriyama and Suzuki [20] evaluated the economic efficiency of nuclear power generation, although it is not in the area of renewable energy, and considered the uncertainty of CO2 emission rights. Szolgayova et al. [21] and Fuss et al. [22] used real options modelling to illustrate how market uncertainty pertaining to fluctuations of carbon price and the carbon price cap policy influence on investment decisions, profits and carbon emissions in electricity sector. Recently Park et al. [23] investigated how uncertain energy policies for carbon emission trading affect the financial viability of the investment in clean development mechanism projects. As for renewable energy, Sarkis and Tamarkin [24] is one of the early attempts which considered greenhouse gas (GHG) trading environment in evaluating investment in renewable energy technologies based on real options analysis. They considered both the stochastic nature of the exercise price of the photovoltaic technology and the market trading price of the GHG emissions. Cheng et al. [25] considered carbon emission reduction as an incentive for renewable energy power generation, while evaluating the economic value of investments in wind power generation using binomial models. Lee and Shih [26] considered the benefits of CO2 emission reduction in presenting a model for evaluating the policy benefits of renewable energy in Taiwan.

These studies are based on the recognition that, as many countries have introduced carbon markets, additional costs of using fossil energy might have been incurred due to carbon emissions. Therefore, although considering only the price of fossil energy which is a substitute good of renewable energy was appropriate for evaluating the economic value of renewable energy in the past, new evaluation models that can consider the impacts of not only fossil energy prices but also carbon emission costs are necessary, given the introduction of carbon emission trading market. However, studies of the economic valuations of renewable energy that consider the factor of carbon markets have been sparse. Furthermore, some recent exploratory studies have also had limitations, as they have not reflected the uncertain characteristics of carbon emission rights prices that are determined by the supply and the demand in the market.

The purpose of the present paper, extended study of the paper previously introduced by Kim and Lee [27], is to develop a real option model that takes into account the uncertainties of both existing fossil energy prices and carbon emission trading prices in evaluating the economic value of renewable energy R\&D investment. Using the real option model, we attempt to assess the effects of the uncertainty of newly appearing carbon markets on the economic value of renewable energy R\&D investment in Korea empirically. Furthermore, we derive an optimal decision path according to the uncertain future situations of fossil energy and carbon markets by analyzing a trinomial lattice model in which the optimal timing of R\&D investment and deployment were identified. Finally, we present relevant policy implications based on the results obtained from this study including sensitivity analysis with respect to important model parameters.

The rest of this paper is organized as follows: Section 2 introduces a real option model by which the effects of carbon markets on the economic value of renewable energy R\&D investment can be evaluated. In Section 3, we briefly describe the data used in this study and present the results of our evaluation using the real option model as well as the results of the sensitivity analysis. Finally, conclusions are drawn in Section 4. 


\section{Model}

\subsection{Carbon Cost Reduction Model}

Let us assume that there are two current energy supply sources of energy: fossil energy and renewable energy, both of which are basically in a substitute relationship. Therefore, if renewable energy prices drop, the ratio of renewable energy to the entire energy supply will increase while that of fossil energy will decrease. In particular, if renewable energy prices will decrease below the level of fossil energy prices owing to the successful results of R\&D for renewable energy, the economic values of this R\&D can be measured as the opportunity costs which would be saved by using cheaper renewable energy compared to fossil energy.

However, once carbon market is introduced, additional cost reduction by using renewable energy should be considered. In general, it is known that renewable energy does not generate carbon emission at all while fossil fuel energy emits large amounts of carbon during the combustion process. And carbon emission will incur costs which would be determined by the carbon market. Therefore, under the recent introduction of carbon markets, it is necessary to consider such costs incurred by carbon emission in evaluating the economic values of renewable energy R\&D. Figure 1 illustrates aforementioned cost reduction structure of renewable energy after the introduction of carbon markets.
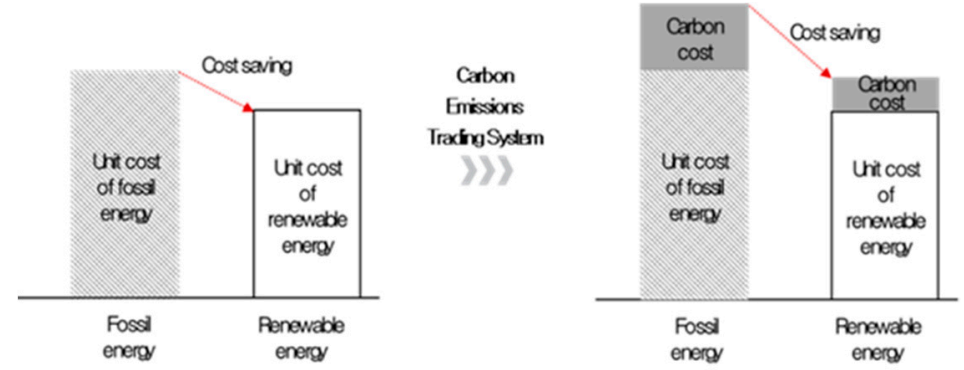

Figure 1. Cost reduction structure after carbon market introduction.

In order to incorporate the effects of carbon emission market in evaluating the economic values of renewable energy $R \& D$, we should assess the amount of cost reduction by using renewable energy due to less or no carbon emission compared to fossil fuel energy. Conceptually this can be calculated by multiplying the amount of carbon emission reductions by the unit price of carbon emission rights. Furthermore, recently Korean government has a long-term renewable energy investment plan by 2030 with a specific goal number year by year [28]. Therefore, in this paper, we define the carbon emission factor as the amounts of carbon emission per unit electric power generated by certain energy source each year and use a year-to-year approach. Let $C E F_{F E}(t)$ denote the carbon emission factor of fossil energy and $C E F_{R E}(t)$ denote the carbon emission factor of renewable energy at year $t$. And let $P_{C E}(t)$ be the unit price of carbon emission rights determined by the carbon emission market at time $t$. Then, if the amount of power generated from renewable energy sources at $t$ is $R E(t)$, the formula for calculating the carbon emission cost reduction of renewable energy can be written as follows:

$$
\left\{C E F_{F E}(t)-C E F_{R E}(t)\right\} \times R E(t) \times P_{C E}(t)
$$

\subsection{Economic Evaluation Model}

In this section, we develop a real option model for the economic evaluation of renewable energy R\&D considering the uncertainty of carbon market based on the previous similar models by Siddiqui et al. and Kim et al. $[13,16]$. Assume that there are three options regarding the R\&D activities of renewable energy - R\&D investment, deployment, and abandonment - and that if the R\&D project has been abandoned or deployed, there will be no R\&D investment any further. The option is an American style call option that the government has the right, not obligation, to abandon, deploy and 
invest the project each time. In the first option, if the effect of $R \& D$ to reduce the cost of renewable energy is expected to be successful, then the decision maker would want to continue funding R\&D. For the second option of deployment, if the results of $R \& D$ have reached a target outcome and the generation cost of renewable energy is sufficiently competitive with that of fossil fuel energy, then commercialization of the results of R\&D should be considered. Abandonment is the third option and can be chosen if there is a reason to stop the on-going R\&D projects [16]. In addition, for the sake of simplicity, we do not consider the uncertainty of R\&D which means that we assume that when $R \& D$ investment option is selected, the cost of using renewable energy will decrease after the $R \& D$ is executed, disregarding the possibility of failure in technology development.

It is assumed that the unit cost of fossil energy power generation and the unit cost of renewable energy power generation follow geometric Brownian motion (GBM). $C_{R E}(t, i)$ corresponds to the unit cost of fossil energy power generation at time $t$, where $i$ is the number of increases in the unit cost by $t$. Then the initial cost of fossil energy power generation can be expressed as $C_{F E}(0,0)$. In the next period, the unit cost will either increase with the probability $p$ or decrease with $1-p$. If the unit cost will increase, then it is calculated by multiplying the initial cost by $u_{1}$, such that $C_{F E}(1,1)=u_{1} C_{F E}(0,0)$. On the contrary if the unit cost will decrease, then it is calculated by multiplying the initial cost by $d_{1}$, such that $C_{F E}(1,0)=d_{1} C_{F E}(0,0)$. Similarly let $P_{C E}(t, j)$ denote the unit price of carbon emission right, where $j$ is the number of increases in unit price by the time period $t$. Suppose that in the next period $P_{C E}(t, j)$ will either go up by the times of $u_{2}$ with the probability $q$ or go down by the times of $d_{2}$ with the probability $1-q$. Therefore, given the initial price of carbon emission right as $P_{C E}(0,0)$, the price of next period can be either $P_{F E}(1,1)=u_{2} P_{F E}(0,0)$ with the probability $q$ or $P_{C E}(1,0)=d_{2} P_{C E}(0,0)$ with the probability $1-q$. We let $\gamma$ be the risk-free interest rate, $\sigma_{1}$ be the past volatility of the unit cost of fossil energy power generation, and $\sigma_{2}$ be the past volatility of the unit price of the carbon emission right, such that $u_{1}=e^{\sigma_{1}}, d_{1}=1 / u_{1}=e^{-\sigma_{1}}, u_{2}=e^{\sigma_{2}}, d_{2}=1 / u_{2}=e^{-\sigma 2}, p=e^{\gamma}-d_{1} / u_{1}-d_{1}$ and $q=e^{\gamma}-d_{2} / u_{2}-d_{2}$.

In our real option model, which considers both the uncertainty of fossil energy costs and the uncertainty of carbon emission rights prices simultaneously, binomial lattices become three-dimensional as shown by Figure 2 .

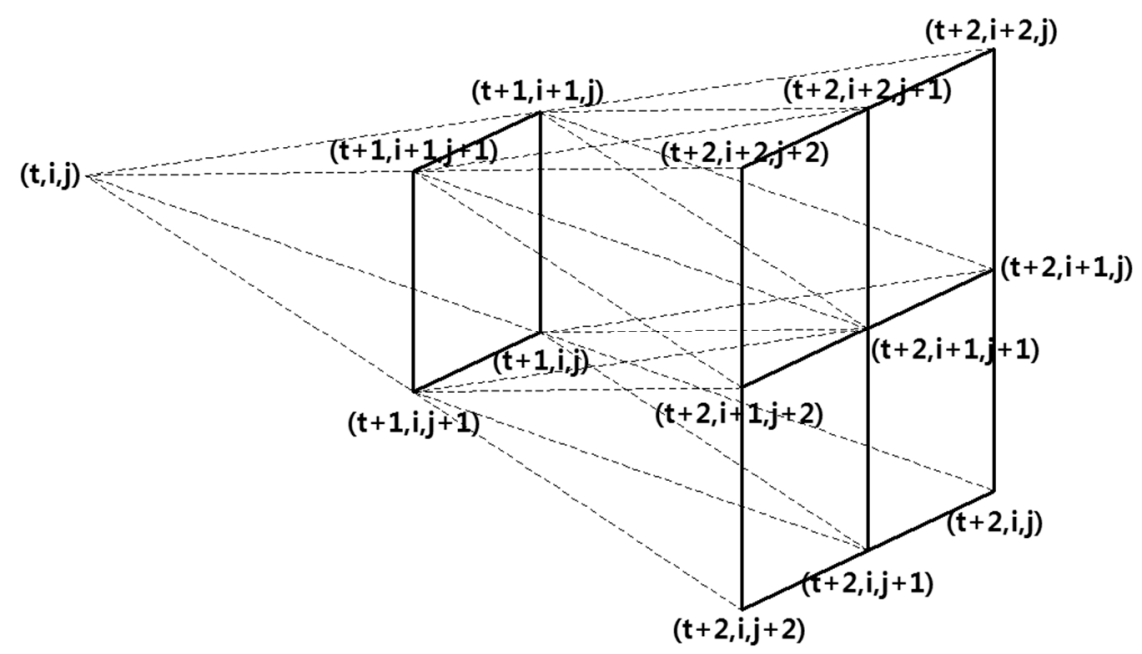

Figure 2. Three-dimensional binomial lattice.

The real option model of this paper addresses the decision problem in which a decision maker (The decision-maker and R\&D investor of this paper can be regarded as the Korean government. In Korea, since the electricity companies which own powerplant are government-owned corporations, the objectives of the government and the electricity companies coincide and this paper assumes that the objective function of R\&D investment is to maximize the future profits of electricity company) 
should choose one of three alternatives among abandonment of the project, deployment, and R\&D investment in each situation and it can be illustrated using decision tree as shown by Figure 3.

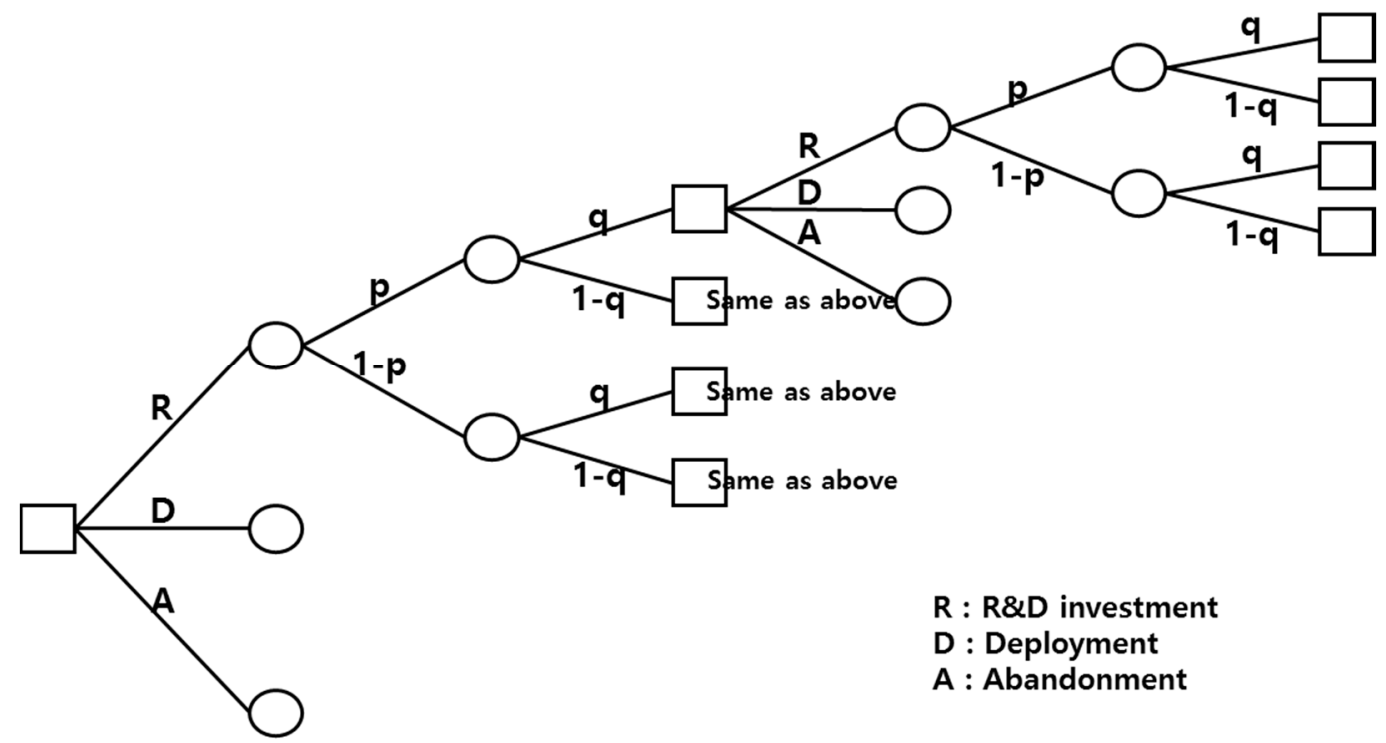

Figure 3. Decision tree.

In Figure 3, if the decision makers choose deployment or abandonment, they no longer have opportunities to continue $R \& D$ investment. On the other hand, if the decision makers select $R \& D$, there are four possible events based on whether fossil energy costs and emission rights prices rise or drop. Each period, in each situation, decision makers repeat the problem of choosing one of three alternatives. Since there are three options available if a new technology resulting from a renewable energy R\&D project has not been deployed or abandoned at any given time $t$, the economic value of renewable energy $R \& D$ investment can be calculated by comparing cash flows under the three options available during an $R \& D$ project repeatedly using the following equation;

$$
V(t, i, j, r)=\operatorname{Max}\left[\begin{array}{l}
\delta\left[\begin{array}{l}
p\{q V(t+1, i+1, j+1, r+1)+(1-q) V(t+1, i+1, j, r+1)\} \\
+(1-p)\{q V(t+1, i, j+1, r+1)+(1-q) V(t+1, i, j, r+1)\}
\end{array}\right]-R D(t) ; \\
\Pi(t, i, j, k) \\
-A(t) ;
\end{array}\right]
$$

In Equation (2), $V(t, i, j, r)$ denotes the economic value of renewable energy R\&D investment at the time period $t$ if the unit cost of fossil energy power generation increases $i$ times, the unit price of carbon emission rights increases $j$ times, and there have been $r$ times of R\&D investment until the time period $t$ (In general, the lag of some periods between R\&D investment and the realization of economic values can be considered in $R \& D$ activities. However, it is known that the lag is likely to be shorter when we consider the application $R \& D$ case compared to the basic research case. In this paper we assumed to ignore the lag effect of R\&D not only because we deals with application R\&D but also because this study has a such long-term study period, 20 years, that the effects of time lag would be little on the economic values of whole study periods.).

The alternative of R\&D investment will be selected when the net present value of choosing $R \& D$ is larger than that of abandonment or deployment. The net present value of R\&D investment can be estimated by deducting the $R \& D$ costs invested now from the future profits expected from investments in renewable energy $R \& D$, and can be expressed as the first row term of Equation (2) as follows:

$$
\delta\left[\begin{array}{c}
p\{q V(t+1, i+1, j+1, r+1)+(1-q) V(t+1, i+1, j, r+1)\} \\
+(1-p)\{q V(t+1, i, j+1, r+1)+(1-q) V(t+1, i, j, r+1)\}
\end{array}\right]-R D(t)
$$


where $R D(t)$ denotes the R\&D expenditure for renewable energy at the time period $t$, and $\delta$ is the discount factor $(\delta=1 /(1+\gamma))$. Thus formula (3) is the sum of the costs incurred by R\&D combined with the present value of the economic values expected to be realized in the future after choosing $R \& D$ investment at the time period $t$.

The alternative of deployment will be selected when the present value of the profit expected from the deployment of technologies developed through renewable energy R\&D is larger than the profit expected from the other alternatives. The profits expected to be generated at time $t$ if the renewable energy technology is commercially deployed at the time period $k$ is denoted by $\Pi(t, i, j, r, k)$, where $i$ is the number of fossil energy cost increases, $j$ is the number of carbon emission price increases, and $r$ is the number of R\&D investments until the time period $t . \Pi(t, i, j, r, k)$, the second row term of Equation (2), can be expressed as follows:

$$
\begin{aligned}
\Pi(t, i, j, r, k) & =\left\{C E F_{F E}(t)-C E F_{R E}(t)\right\} \times P_{C E}(t, j) \times R E(t, k) \\
& +\left\{C_{F E}(t, i)-C_{R E}(t, r)\right\} \times R E(t, k) \\
& +\delta\left[\begin{array}{c}
p\{q \Pi(t+1, i+1, j+1, r, k)+(1-q) \Pi(t+1, i+1, j, r, k)\} \\
+(1-p)\{q \Pi(t+1, i, j+1, r, k)+(1-q) \Pi(t+1, i, j, r, k)\}
\end{array}\right] .
\end{aligned}
$$

In Equation (4), the first term represents the carbon emission cost reduction which was explained in equation (1) in detail. Note that $P_{C E}(t, j)$ is the unit price of carbon emission rights at time $t$ if the number of price increases is $j$ and $R E(t, k)$ stands for the amount of power generated from renewable energy sources at the time period $t$ if the renewable technology developed from R\&D is deployed at time period $k$. The second term implies the power generation cost reduction due to the use of renewable energy that is cheaper than fossil energy after deployment at time period $k$. The final term is present value of the expected future revenues after the deployment at time $t$ considering four combinations of the up and down of both fossil energy cost and carbon emission rights price.

In the case that fossil energy prices and carbon emission rights prices continue to decline such that the current $R \& D$ costs are regarded as being larger than the revenues expected from implementing renewable energy $R \& D$, the decision-maker can abandon the project to reduce losses. Let the third row term of Equation (2), $-A(t)$, denote the loss incurred by selecting abandonment at time $t$. In this paper, the amount of loss is assumed to be equal to the total investment into the renewable energy R\&D by time $t$.

In the end, the final option value, expressed as $V(0,0,0,0)$, can be obtained by backward induction using Equation (2).

\section{Analysis}

\subsection{Data}

The data analyzed in the present study are summarized in Table 1 and the details are reviewed as follows.

The time period evaluated in this study was set as 14 years, assuming the first year to be 2014 considering data availability. The risk-free interest rate, $\gamma$, was set to $3.60 \%$, which is the average of the annual interest rate on 91-day CDs (certificate of deposits) for the last 10 years. The unit cost of fossil energy generation was estimated based on the power trading volumes by fossil energy source, the amounts of power trading, and the ratios of the amounts of power trading by fossil energy source provided in the Electric Power Statistics Information System (EPSIS) of the Korea Power Exchange [29]. As a result, the first year's unit cost of fossil energy generation was estimated to be $89.17 \mathrm{KRW} / \mathrm{kWh}$. In general, the renewable energy investment by Korean government has been largely categorized into 'investment for demonstration \& deployment, and 'R\&D investment' for renewable energy and therefore any relevant data has been measured and aggregated according to these categories [28]. Based on the data of 'R\&D investment' for renewable energy, it is assumed that $R \& D$ investment of 
renewable energy in South Korea will continue to be 500 billion KRW according to the Korea Energy Agency [28].

Table 1. Input parameters.

\begin{tabular}{cccc}
\hline Variable & Description & Unit & Value \\
\hline$N$ & Number of time periods & Years & 14 \\
$\gamma$ & Risk-free interest rate & $\%$ & 3.60 \\
$\delta$ & Discount factor & $\mathrm{KRW} / \mathrm{kWh}$ & 0.965 \\
$C_{F E}(0,0)$ & Initial cost of fossil energy generation & $\mathrm{KRW} / \mathrm{kWh}$ & 89.17 \\
$C_{R E}(0,0)$ & Initial price of renewable energy generation & $\mathrm{tCO}_{2} / \mathrm{MWh}$ & 169.09 \\
$C E F_{F E}(t)$ & Carbon emission factor of fossil energy & $\mathrm{tCO}_{2} / \mathrm{MWh}$ & 0.4485 \\
$C E F_{R E}(t)$ & Carbon emission factor of renewable energy & $\mathrm{KRW}_{\mathrm{tCO}}$ & 0.0000 \\
$P_{C E}(0,0)$ & Initial price of carbon emission rights & Billion $\mathrm{KRW}$ & 10,000 \\
$R D(t)$ & R\&D expenditure & $\%$ & 500 \\
$\sigma_{1}$ & Fossil energy cost volatility & $\%$ & $25.06 / / 40.93 / 75.14$ \\
$\sigma_{2}$ & Carbon emission rights price volatility & & 62.85 \\
\hline
\end{tabular}

In Korea, due to the lack of economic efficiency of renewable energy power generation, renewable energy power generation companies are currently receiving government subsidies to encourage the renewable energy supply. A representative subsidy system is the Feed-in Tariff (FIT) system, which was introduced and became effective from March 2002 and terminated in December 2011. The FIT system compensated for differences when power supply prices were lower than the FIT prices officially set by the government for photovoltaic power, wind power, small hydro-power, tidal power, bio energy, waste incineration power, and fuel cell power generation. Therefore, in the case of renewable energy, the subsidies paid in addition to the unit cost of power generation should be reflected in cost estimation. In the present study, the unit costs of renewable energy were estimated as the sum of the unit costs of power generation and unit compensations for differences. The unit costs of power generation were estimated using the data on the amounts of power trading and the power trading volumes by renewable energy sources provided also in the EPSIS of the Korea Power Exchange [29]. The unit compensations for differences were obtained from the generation quantities of facilities supported by the FIT system and subsidy data contained in the New \& Renewable Energy White Paper [3]. As a result, the unit cost of renewable energy was calculated as $169.09 \mathrm{KRW} / \mathrm{kWh}$.

Although the production of renewable energy is vulnerable to natural conditions from a short-term and micro-scale viewpoint, if we consider a renewable energy production in a large area like a whole territory of one country and in a long-term year, the sensitivity to weather condition can be considerably mitigated. Henceforth, it is assumed that there would no drastic change in the nature condition, and thereby renewable energy production will be subject to not by natural condition but by market and policy conditions since this paper addresses a nation-wide and long-term analysis. In the Sixth Basic Plan for Long-Term Electricity Supply and Demand (2013-2027) [30], the base power demand in 2027 was forecasted to be 771,007 GWh, and the supply of renewable energy to be 90,134 GWh, accounting for approximately $11.69 \%$ of supply for the total power demand (Ministry of Knowledge Economy, 2013). In 2014, the total power demand was 505,315 GWh and the quantity of renewable energy power generation was $20,080 \mathrm{GWh}$, which is approximately $3.97 \%$ of the total power demand. In this study, the ratio of renewable energy to the total power demand was assumed to be $3.97 \%$ in the first year of deployment while $11.69 \%$ in the last year, as targeted by the government (According to the Korean government's renewable energy plan, the fossil-fueled plant will not be totally retired even if the economic competitiveness of renewable energy is better than that of fossil fuel energy. However, the government plans that no more fossil-fueled power plant shall be constructed newly and the old ones that have been operated longer than its economic life will be shut down. Therefore, the portion of the fossil-fueled plant and the amount of energy generation will be lowered as the amount of renewable energy generation increases due to its economic competitiveness.). 
The carbon emission factor of fossil energy was estimated using the data about the greenhouse gas emission factor of generation-terminal in the electric power sector presented by the Korea Power Exchange from 2008 to 2011, and the average value of the 4 years, 0.4485, was applied [29]. Although the data set include renewable energy as well as fossil energy, since the ratio of renewable energy to the total power generation was insignificant, we assume that the carbon emission factor of the fossil energy is the same as the greenhouse gas emission factor of generation-terminal. The carbon emission factor for renewable energy was assumed to be zero.

The carbon emission rights price was set as 10,000 $\mathrm{KRW} / \mathrm{tCO}_{2}$-eq, which is the standard price of the Korean Allowance Unit(KAW) established on January 12, 2015. Note that the unit of carbon emission rights, $\mathrm{tCO}_{2}$-eq, is a carbon dioxide equivalent ton, which refers to one ton of carbon dioxide, or the quantity of each of the other greenhouse gases (methane $\left(\mathrm{CH}_{4}\right)$, nitrous oxide $\left(\mathrm{N}_{2} \mathrm{O}\right)$, hydrofluorocarbons (HFCs), perfluorinated carbons (PFCs), and sulfur hexafluoride $\left(\mathrm{SF}_{6}\right)$ ) that has an equivalent effect on global warming, pursuant to clause 9 of article 2 of the Framework Basic Act on Low Carbon Green Growth.

In this study, the volatilities of fossil energy cost and carbon emission rights price should be considered in real option models. In Korea, most power generation other than nuclear power relies on coal (bituminous coal, anthracite), natural gas (LNG), and petroleum (light oil, heavy oil). Thus, the volatility of fossil energy costs was estimated based on the prices of coal, natural gas, and petroleum over the 15-year period from January 2000 to December 2014. The volatility of coal prices was estimated from the Australian coal price data in the commodity price data provided by the World Bank, and the coal price volatility was derived as $25.06 \%$. The volatility of natural gas prices was based on the spot price data from Henry Hub Natural Gas provided by the Energy Information Administration (EIA) and was derived as $75.14 \%$. The volatility of petroleum prices was estimated from the WTI crude oil spot price data provided by the EIA, and it was calculated as $38.36 \%$.

Unlike the EU, which has the largest carbon market in the world, the US has no obligation to reduce greenhouse gas emissions, as it has withdrawn from the Kyoto Protocol convention. However, carbon emission rights are traded in carbon markets operated or planned in certain state governments such as California and the Chicago Climate Exchange (CCX) is the most representative example of these voluntary carbon markets. South Korea is not yet in the period of obligatory reductions pursuant to the Kyoto Protocol, but has voluntarily formed and is operating a carbon market. Therefore, in the present study, attempts were made to estimate the volatility of carbon emission rights prices based on the carbon emission rights prices determined through trading in the CCX, which has characteristics similar to those of the South Korean carbon market. The volatility of carbon emission rights price in the CCX for the 6-year period from January 2004 to December 2009 was $62.85 \%$.

\subsection{Evaluation of Economic Values of Renewable Energy RED}

If the passive economic value of certain investment calculated by discounted cash flow models is termed the static net present value (SNPV), the intrinsic value including the option value is termed the expanded NPV (ENPV), and the option value is termed the real option value (ROV), the relationship can be expressed as follows [31]:

$\mathrm{ENPV}=\mathrm{SNPV}+\mathrm{ROV}$

Therefore, it can be seen that an ENPV derived through analysis of the real option model is the sum of the SNPV (a static investment value not including any option) and the ROV (the value of the flexibility termed option).

The purpose of the present study was to analyze the economic effects of the uncertainty of carbon emission rights prices on the values of renewable energy R\&D investment. A conceptual illustration of analysis procedure to that end is presented in Figure 4. In Figure 4, 'A' refers to the static NPV which is the economic values from the reduction in generation costs resulting from the use of renewable energy instead of fossil energy, ' $\mathrm{B}^{\prime}$ refers to the option value resulting from the flexibility of decision-making to cope with the uncertainty of fossil energy prices, ' $C$ ' refers to the reduction in carbon emission costs 
resulting from the replacement of fossil energy with renewable energy, and ' $D$ ' refers to the option value resulting from the uncertainty of carbon emission rights prices, which is the effect of the volatility of carbon emission rights prices on the economic value of renewable energy R\&D.
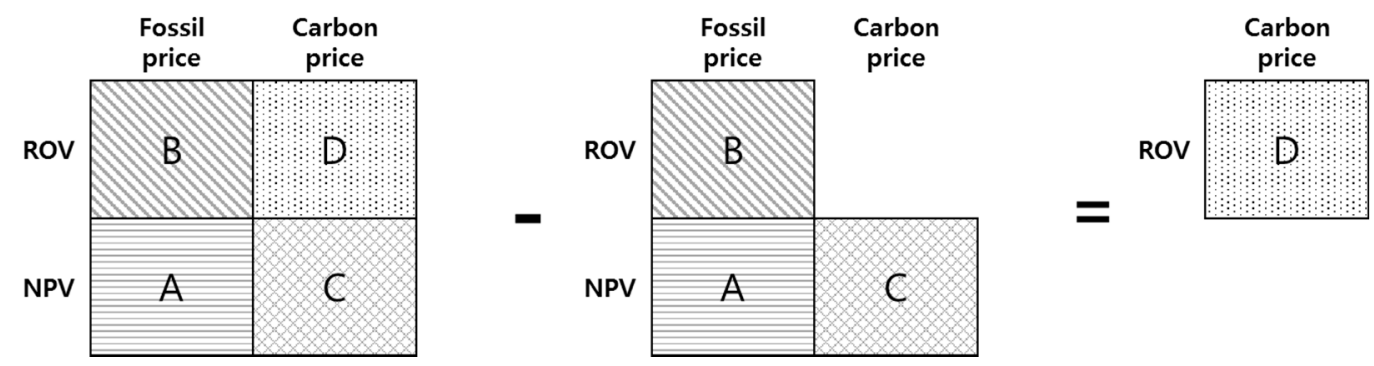

Figure 4. Conceptual procedure of calculating the economic effects of carbon market uncertainty.

Therefore, the part that the present study aims to quantify in monetary value corresponds to ' $\mathrm{D}$ ' in Figure 4, which can be derived by comparing the results of economic values with and without consideration of the volatility of carbon emission rights prices in our real option model. That is, the economic values which consider the volatilities of both fossil energy costs and carbon emission rights prices simultaneously would correspond to ' $\mathrm{A}+\mathrm{B}+\mathrm{C}+\mathrm{D}$ '. On the other hand, the economic values in which the volatility of carbon emission rights prices were set to 0 correspond to ' $A+B+C$ ' because the option value due to the uncertainty of carbon emission rights prices did not occur. Therefore, the option value resulting from the uncertainty of carbon emission rights prices could be obtained by deducting the latter value from the former economic value.

One of the most important factors in real option analyses is the volatility necessary to reflect uncertainty. South Korean fossil energy power generation records indicate that most power generation other than nuclear power relies on coal (bituminous coal, anthracite), LNG, and petroleum (light oil, heavy oil). Considering this fact, this paper established volatility scenarios based on the historical data of the prices of coal, natural gas, and petroleum as follows:

- Standard volatility scenario: $40.93 \%$ (a scenario considering the ratios of power generation using coal, petroleum, and natural gas in South Korea over the last 10 years and the volatility of coal, petroleum, and natural gas prices over the last 15 years)

- Low volatility scenario: $25.06 \%$ (a scenario based on coal price volatility over the last 15 years)

- High volatility scenario: $75.14 \%$ (a scenario based on natural gas price volatility over the last 15 years)

In the present study, the volatility of carbon emission rights prices was estimated based on the carbon emission rights prices for trading at the CCX during the six-year period from January 2004 to December 2009 , and as a result the value of $62.85 \%$ was applied for.

The calculation results of the economic values of renewable energy R\&D considering the uncertainties of both fossil energy costs and carbon emission rights prices using the real option model of Equation (2) are shown in Table 2.

Table 2. Economic values of renewable energy R\&D (Unit: Billion KRW).

\begin{tabular}{cccc}
\hline Scenario & A + B + C + D & A + B + C & D \\
\hline High volatility & $29,859.2$ & $29,556.6$ & 302.6 \\
Standard volatility & $16,229.9$ & $15,786.5$ & 443.4 \\
Low volatility & 8653.8 & 8129.4 & 524.4 \\
\hline
\end{tabular}

The results show that the ENPV of renewable energy R\&D ranges from 8653.8 billion KRW to $29,859.2$ billion KRW and the option value resulting from the uncertainty of carbon emission rights 
prices ranges from 302.6 billion KRW to 524.4 billion KRW according to the scenarios of the volatility of fossil energy costs. It is verified that the ENPV of renewable energy R\&D increases while the option value decreases as the volatility of fossil energy costs increases. This means that when the volatility of fossil energy prices is lower, the volatility of carbon emission rights prices has greater effects on the economic value of renewable energy $R \& D$.

The three-dimensional schematization of the optimal decision lattice for the standard volatility scenario as a representative case among fossil energy price volatility scenarios is shown in Figure 5, where ' $A$ ' indicates abandonment, ' $D$ ' indicates deployment, and ' $R$ ' indicates $R \& D$ investment. And $(t, i, j)$ at each node refers to cases where fossil energy prices rose $i$ times and carbon emission rights prices rose $j$ times at time $t$. To examine the optimal decisions in this scenario, in the outset of our analysis, R\&D investment is an optimal decision; likewise, in the consecutive two years, continuously investing in $\mathrm{R} \& \mathrm{D}$ (regardless of whether fossil energy prices and carbon emission rights prices rise or drop) is an optimal decision. If fossil energy prices continuously drop and carbon emission rights prices drop one or more times before the fourth year, to abandon R\&D investment in renewable energy will be optimal. On the other hand, if fossil energy prices continuously rise until the fourth year, then it is optimal to deploy the renewable energy technologies developed through R\&D.

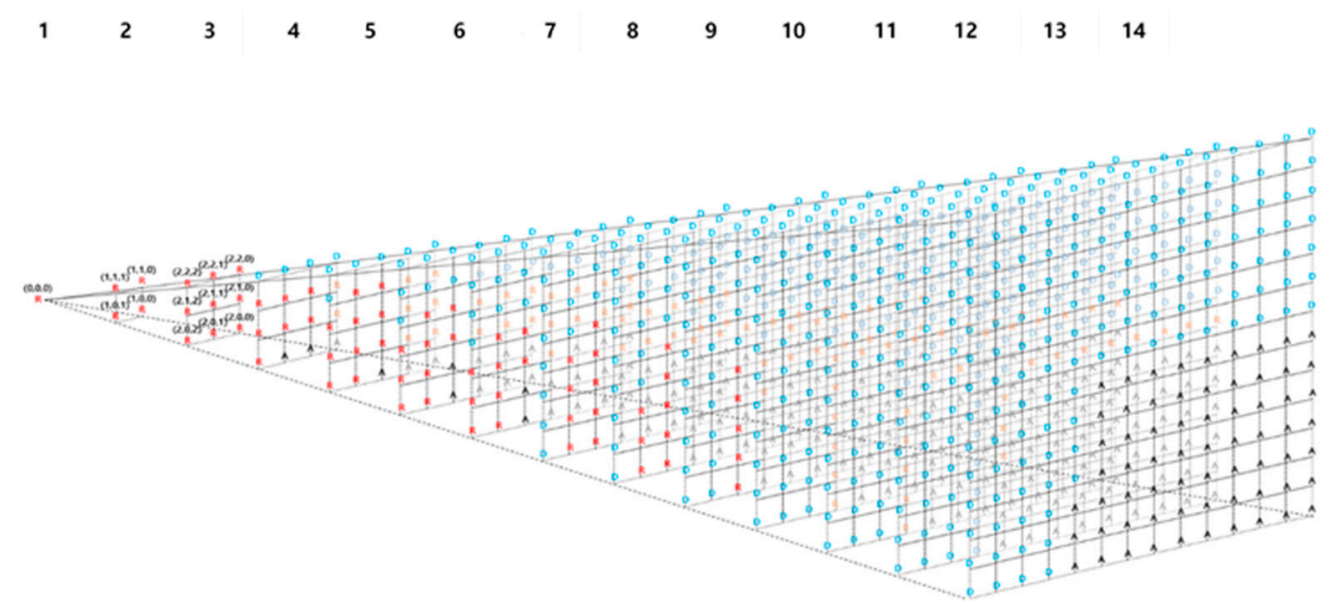

Figure 5. Three-dimensional optimal decision lattice in standard volatility scenario (A: abandonment, D: deployment, R: R\&D investment).

The optimal decision can be interpreted in more detail as follows. First, if fossil energy prices continuously drop and carbon emission rights prices drop one or more times by the fourth year, it is anticipated that the expected profits by lowering the unit costs of renewable energy than fossil energy through $R \& D$ will be smaller than the current $R \& D$ costs. Therefore, the decision-maker would rather abandon than continue the R\&D in order to reduce further losses.

Second, we know that the earlier is renewable energy technology deployed in market, the more we will be able to use renewable energy to generate power in the future. Thus, once the unit costs of renewable energy become cheaper than fossil energy, there is a trade-off between securing larger amount of renewable energy generation in the future and reducing renewable energy costs more by further R\&D investments. If the revenue from securing larger renewable energy generation quantities in the future while maintaining the renewable energy costs at the current level is higher, the decision-maker will select the deployment option. However, if the revenue from increasing the difference of unit power costs by reducing renewable energy costs while bearing some losses in the renewable energy generation quantities that can be secured in the future is higher, the decision-maker will select to continue R\&D investment. Therefore, if fossil energy prices continuously rise until the fourth year, the revenue that can be obtained by selecting deployment will likely be higher than the revenue from $R \& D$ investment, so the decision-maker will select the alternative of deployment. 
A binomial lattice displaying the results of each option value when we only consider the uncertainty of fossil energy prices from Figure 5 for the sake of two-dimensional representation is shown in Table 3. In Table 3, fossil energy prices move horizontally when they rise and move diagonally downward when they drop. For instance, the results of the first year show that a revenue of 500 billion KRW is expected if abandonment is selected, $-24,496.2$ billion KRW if deployment is selected, and 16,229.9 billion KRW if $R \& D$ investment is selected. Therefore, in the first year, investing in R\&D is optimal, which is highlighted in grey color. Similarly, in the second year, it is found that investing in R\&D is optimal regardless of the movements of fossil energy prices. However, in the fourth year, the optimal option will be different according to the fossil energy price movements; in the case that fossil energy prices rise until the fourth year, deployment the R\&D result is optimal while in the case that fossil energy prices drop until the fourth year, a node that recommends the option of abandonment appears. Finally, in Figure 6 we summarize the optimal decisions for each node of fossil energy prices movements of Table 3 as a two-dimensional lattice diagram.

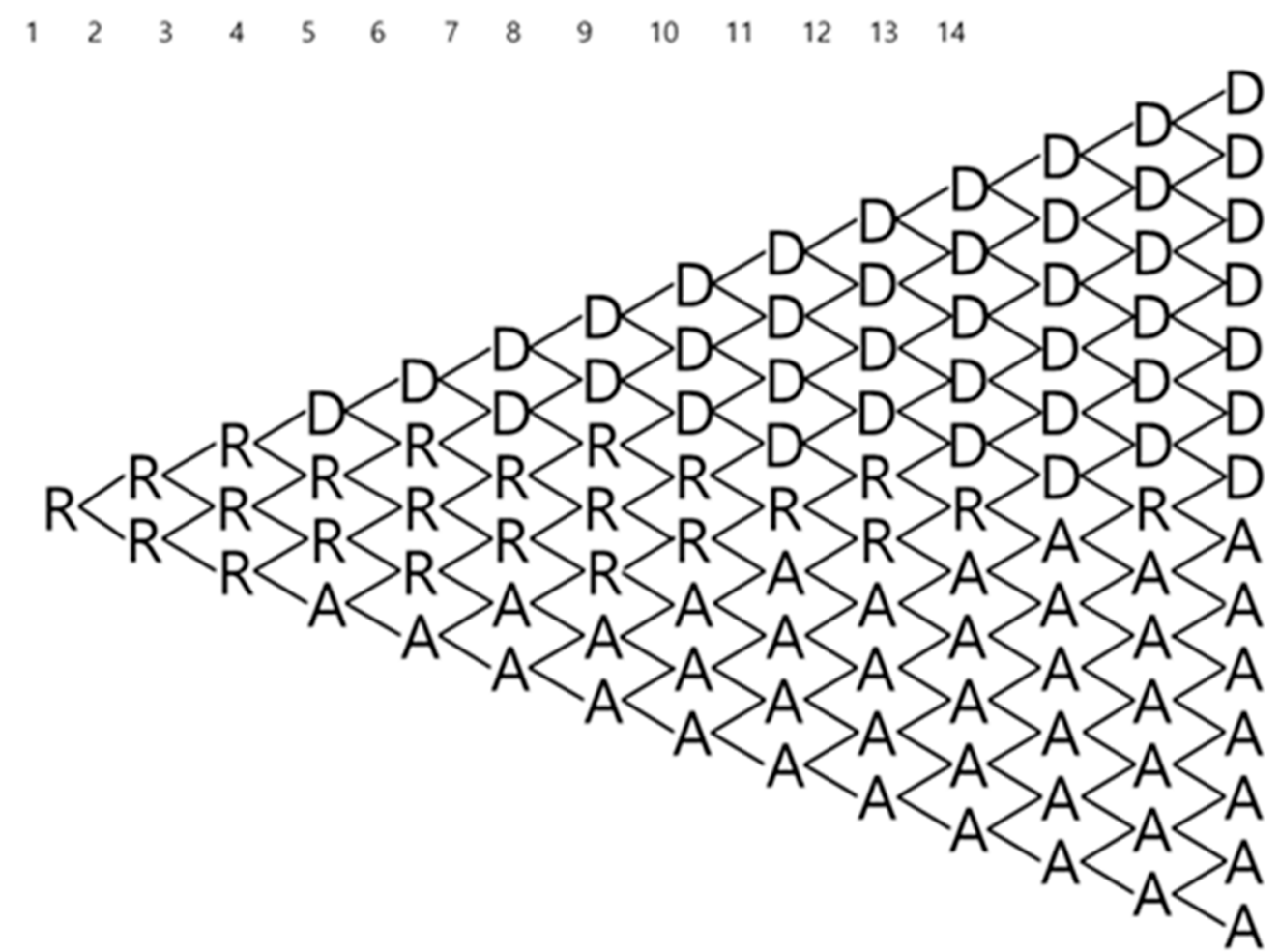

Figure 6. Two-dimensional optimal decision lattice considering fossil energy prices uncertainty (A: abandonment, D: deployment, R: R\&D investment).

\subsection{Sensitivity Analysis}

Among the factors that affect the economic value of renewable energy R\&D, the following variables were selected as affecting factors in sensitivity analyses: the volatility of fossil energy price, the volatility of carbon emission rights price, the risk-free rate, the decreasing rate of the unit cost of renewable energy power generation, and the quantity of renewable energy generation. The sensitivity analyses were conducted based on the following standards: a fossil energy price volatility of $40.93 \%$, a carbon emission rights price volatility of $62.85 \%$, a risk-free rate of $3.60 \%$, and a decreasing rate of renewable energy cost of $3 \%$. The results of the sensitivity analyses are shown in Figure 7. 
Table 3. Binomial lattice of option values (Unit: Billion KRW).

\begin{tabular}{|c|c|c|c|c|c|c|c|c|c|c|c|c|c|c|}
\hline$t$ & 1 & 2 & 3 & 4 & 5 & 6 & 7 & 8 & 9 & 10 & 11 & 12 & 13 & 14 \\
\hline A & -500 & -500 & -500 & -500 & -500 & -500 & -500 & -500 & -500 & -500 & -500 & -500 & -500 & -500 \\
\hline D & $-24,496$ & 11,513 & 52,701 & 113,062 & 187,194 & 289,163 & 416,061 & 579,865 & 775,228 & $1,001,645$ & $1,231,780$ & $1,416,505$ & $1,442,444$ & $1,635,679$ \\
\hline \multirow[t]{38}{*}{$\mathrm{R}$} & 16,230 & 33,580 & 60,812 & 108,384 & 172,752 & 262,072 & 370,044 & 504,204 & 654,497 & 811,067 & 934,396 & 954,539 & $1,083,233$ & \\
\hline & & -500 & -500 & -500 & -500 & -500 & -500 & -500 & -500 & -500 & -500 & -500 & -500 & -500 \\
\hline & & $-40,278$ & $-20,180$ & 11,241 & 46,148 & 95,773 & 154,221 & 230,942 & 319,853 & 423,991 & 528,505 & 614,034 & 628,763 & 716,036 \\
\hline & & 5998 & 12,466 & 26,964 & 50,259 & 88,340 & 138,183 & 201,605 & 270,643 & 343,737 & 401,150 & 413,844 & 472,126 & \\
\hline & & & -500 & -500 & -500 & -500 & -500 & -500 & -500 & -500 & -500 & -500 & -500 & -500 \\
\hline & & & $-52,320$ & $-33,662$ & $-16,055$ & 10,487 & 38,748 & 77,064 & 119,029 & 169,241 & 218,356 & 260,139 & 269,924 & 310,467 \\
\hline & & & 719 & 3947 & 8974 & 20,662 & 39,528 & 68,157 & 101,360 & 137,642 & 165,985 & 175,394 & 202,623 & \\
\hline & & & & -500 & -500 & -500 & -500 & -500 & -500 & -500 & -500 & -500 & -500 & -500 \\
\hline & & & & $-53,465$ & $-43,486$ & $-27,125$ & $-12,176$ & 9203 & 30,465 & 56,894 & 81,578 & 104,069 & 111,673 & 131,608 \\
\hline & & & & -573 & 42 & 2209 & 6016 & 15,167 & 28,326 & 46,752 & 62,276 & 70,235 & 83,770 & \\
\hline & & & & & -500 & -500 & -500 & -500 & -500 & -500 & -500 & -500 & -500 & -500 \\
\hline & & & & & $-55,584$ & $-43,712$ & $-34,634$ & $-20,724$ & -8593 & 7348 & 21,258 & 35,241 & 41,883 & 52,730 \\
\hline & & & & & -983 & -877 & -478 & 840 & 3,324 & 9,804 & 16,671 & 23,860 & 31,355 & \\
\hline & & & & & & -500 & -500 & -500 & -500 & -500 & -500 & -500 & -500 & -500 \\
\hline & & & & & & $-51,027$ & $-44,538$ & $-33,922$ & $-25,818$ & $-14,502$ & $-5,344$ & 4887 & 11,105 & 17,944 \\
\hline & & & & & & -983 & -983 & -983 & -877 & -137 & 1137 & 4660 & 8240 & \\
\hline & & & & & & & -500 & -500 & -500 & -500 & -500 & -500 & -500 & -500 \\
\hline & & & & & & & $-48,906$ & $-39,743$ & $-33,414$ & $-24,138$ & $-17,075$ & -8499 & -2468 & 2,603 \\
\hline & & & & & & & -983 & -983 & -983 & -983 & -983 & -612 & 198 & \\
\hline & & & & & & & & -500 & -500 & -500 & -500 & -500 & -500 & -500 \\
\hline & & & & & & & & $-42,310$ & $-36,764$ & $-28,387$ & $-22,249$ & $-14,403$ & -8454 & -4162 \\
\hline & & & & & & & & -983 & -983 & -983 & -983 & -983 & -983 & \\
\hline & & & & & & & & & & -500 & & -500 & -500 & -500 \\
\hline & & & & & & & & & $-38,241$ & $-30,261$ & $-24,531$ & $-17,006$ & $-11,093$ & -7146 \\
\hline & & & & & & & & & & -983 & -983 & -983 & -983 & \\
\hline & & & & & & & & & & -500 & -500 & -500 & -500 & -500 \\
\hline & & & & & & & & & & $-31,088$ & $-25,537$ & $-18,154$ & $-12,258$ & -8462 \\
\hline & & & & & & & & & & -983 & -983 & -983 & -983 & \\
\hline & & & & & & & & & & & & -500 & -500 & -500 \\
\hline & & & & & & & & & & & $-25,981$ & $-18,660$ & $-12,771$ & -9042 \\
\hline & & & & & & & & & & & -983 & -983 & -983 & \\
\hline & & & & & & & & & & & & -500 & -500 & -500 \\
\hline & & & & & & & & & & & & $-18,884$ & $-12,998$ & -9298 \\
\hline & & & & & & & & & & & & & & \\
\hline & & & & & & & & & & & & & -500 & -500 \\
\hline & & & & & & & & & & & & & $\begin{array}{c}-13,097 \\
-983\end{array}$ & -9411 \\
\hline & & & & & & & & & & & & & & -500 \\
\hline & & & & & & & & & & & & & & -9460 \\
\hline
\end{tabular}




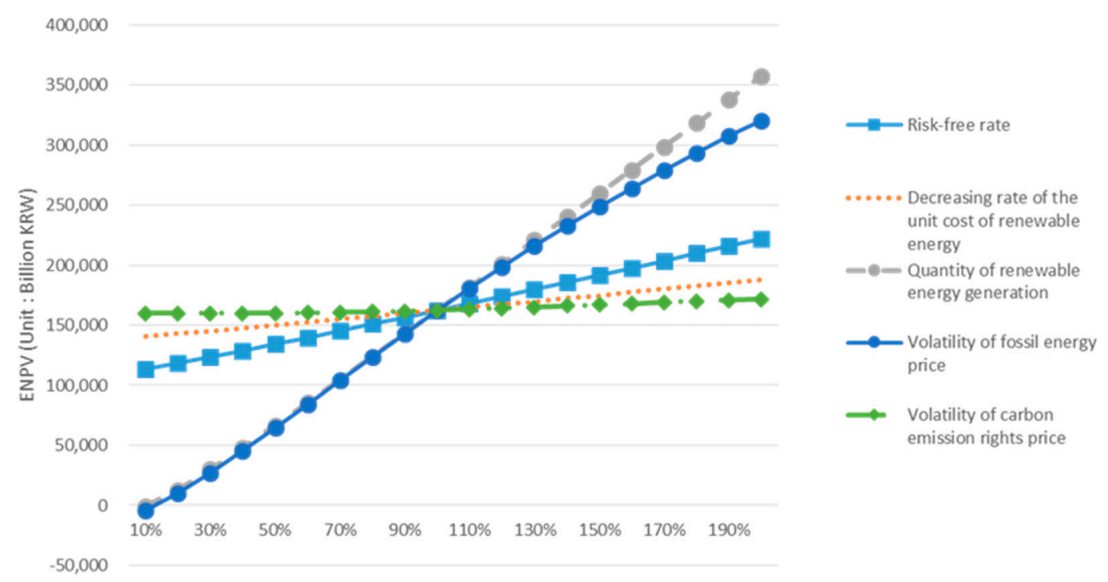

Figure 7. Results of sensitivity analyses on expanded net present value (ENPV).

According to the results of sensitivity analyses, it is found that there exists a positive relationship between the economic value of renewable energy $R \& D$ and each of the affecting variables. Among them, the most sensitively affecting variable on the economic value of renewable energy R\&D was proven to be the quantity of renewable energy generation, followed by fossil energy price volatility, the risk-free rate, the decreasing rate of renewable energy power generation costs, and carbon emission rights price volatility. The reason that the most influential factor is the renewable energy generation quantity could be explained such that revenues after deployment directly depend on the amount of renewable energy power generation as well as there could be large differences in the whole available quantities of renewable energy power generation by the last year according to the timing points of deployment.

The result that the degree of sensitivity of renewable energy quantity is larger than the decreasing rate of renewable energy cost can be interpreted that the economic value of renewable energy $R \& D$ is more sensitively varied with the total supply than the factor of technological competitiveness.

We attempted one more sensitivity analysis to examine the effect of the uncertainty of carbon emission rights prices on the option values of renewable energy R\&D. The graphs of Figure 8 showed that ROV increases as the volatility of carbon emission rights prices increases. In addition, when the volatility of fossil energy prices is lower, the economic effect of the option value resulting from the uncertainty of carbon emission rights prices becomes larger. Through this result, it can be inferred that when the uncertainty of fossil energy prices is lower, there could be more incentives for the aggressive investments in the renewable energy to reduce carbon emission to cope with the uncertainty of carbon emission rights prices because the economic values of the flexibility of decision-making become higher.

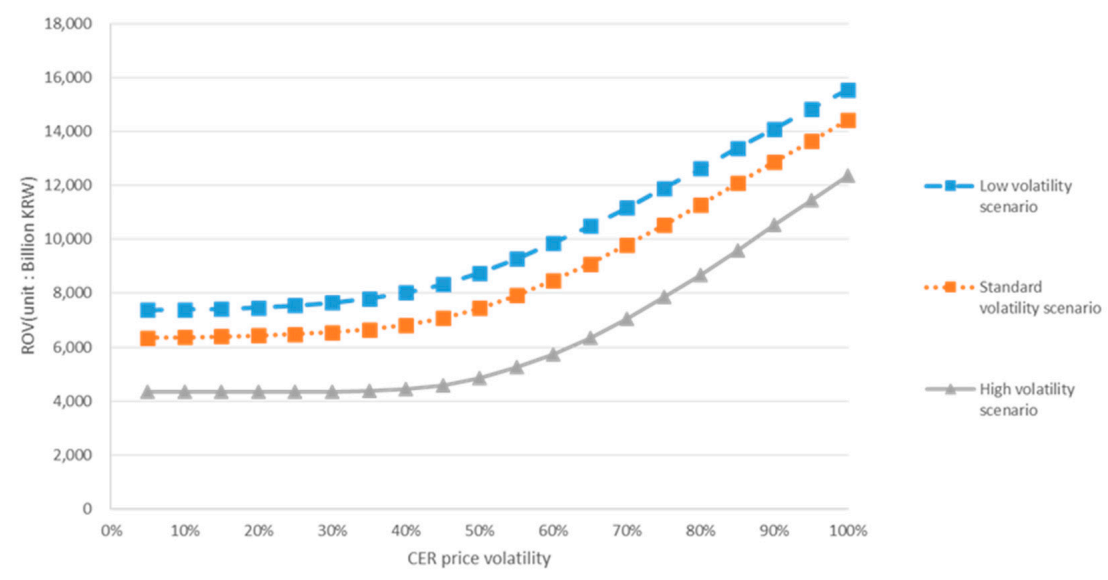

Figure 8. Results of sensitivity analyses on real option value (ROV). 


\section{Conclusions}

In Korea since the start of the carbon emission trading system on January 1, 2015, there have been low volumes of trade on the allowance market. No transactions took place between January 16 and October 6, 2015, and the total transaction volume of Korean Allowance Units (KAUs) in 2015 was $0.3 \mathrm{MtCO}_{2} \mathrm{e}$, representing a small share of the $573 \mathrm{MtCO}_{2} \mathrm{e}$ cap. In 2016, trade remains limited-as of August 1, 2016 the most recent trade took place on July 22, 2016 at KRW17,000/tCO $2 \mathrm{e}$ (US\$15/tCO2e) [32]. Since one of the goals of implementing the carbon emission trading system is the development of a market mechanism to motivate the transformation of energy consumption structure from fossil fuel to green energy like renewable energy, there would be a close relationship between the introduction of carbon emission market and the investments in renewable energy. Thus, the importance of renewable energy as potential sources of reducing greenhouse gases emission necessitates a research that investigates the effects of the uncertainty of carbon market on the economic viability of the investments in renewable energy.

In this study, we developed a real option model for evaluating the economic value of renewable energy R\&D investment considering the uncertainties of not only the existing fossil energy market but also the newly starting market of carbon emission trade. Furthermore, we empirically estimated the effects of the uncertainty of carbon emission market on the economic value of renewable energy R\&D investment. As a result, the option value ranging from about 300 billion KRW to 525 billion KRW would be the positive effects resulting from the uncertainty of carbon emission rights prices on the economic values of renewable energy R\&D investment in Korea. According to the results of the sensitivity analyses, the variable that affected the economic value of renewable energy $R \& D$ investment the most sensitively was the expected whole amount of renewable energy generation in the future. This may partially explain the fact that Korean government's initial renewable energy policies were focused on supply-oriented projects and accordingly renewable energy-related budgets have been allocated largely to the policy for supply expansion compared to other policies like technology development.

Furthermore, using the real option analysis results, we generated trinomial lattices and used them to suggest optimal strategic decision-making choices with respect to situational changes in both markets' uncertainties. Our results can be used as basic data when renewable energy-related policies are established, and when diverse stakeholders in the renewable energy area are making decisions about investing in renewable energy R\&D. Regarding the direction of future studies, it is necessary to reflect the fact that the efficiency of $R \& D$ varies with the amount of investment in $R \& D$ when considering the decreasing rates of renewable energy costs prices in real option model by applying models such as learning curve. In addition, since the present study assumed that the carbon emission factor of renewable energy was zero for the sake of simplicity, actual carbon emission factors of renewable energy should be applied in future studies, and studies considering the relationship between renewable energy $R \& D$ and carbon emission factors should be conducted. Moreover, although the present study assumed that fossil energy prices and carbon emission rights prices were independent from each other, if data on carbon emission rights prices for trading in carbon markets are sufficiently accumulated, the correlation between the two prices should be analyzed and the results should be modeled accordingly. In addition, since R \& D uncertainty is one of the significant factors in evaluating the economic values of renewable energy $R \& D$, as a further study, it is necessary to consider R \& D success rate in a real option model for evaluation of R\&D investment like Jang et al. [15]. Finally, in order to properly model the effects of stationarity and long range dependence of carbon dioxide emission on the energy market and structural breaks of carbon emission rights prices, the development of real option models using fractional Brownian motion will be needed for further study.

Author Contributions: Conceptualization, K.-T.K. and D.-J.L.; methodology, K.-T.K. and D.-J.L.; formal analysis, K.-T.K.; data curation, K.-T.K.; writing-original draft preparation, K.-T.K. and D.-J.L.; writing-review and editing, D.A.; visualization, D.A.; funding acquisition, D.-J.L. All authors have read and agreed to the published version of the manuscript. 
Funding: This work was supported in part by Basic Science Research Program through the National Research Foundation of Korea(NRF) funded by the Ministry of Science, ICT and Future Planning (NRF-2015R1A2A1A15056066). This work was also supported in part by Basic Science Research Program through the National Research Foundation of Korea(NRF) funded by the Ministry of Science, ICT and Future Planning (NRF-2017R1A2B2005894).

Conflicts of Interest: The authors declare no conflict of interest.

\section{References}

1. Kossoy, A.; Oppermann, K.; Platonova-Oquab, A.; Suphachalasai, S.; Höhne, N.; Klein, N.; Gilbert, A.; Lam, L.; Toop, G.; Wu, Q.; et al. State and Trends of Carbon Pricing 2014; World Bank: Washington, DC, USA, 2014.

2. Sawin, J.L.; Sverrisson, F.; Chawla, K.; Lins, C.; Adib, R.; Hullin, M.; Leitner, S.; Mazzaccaro, S.; Murdock, H.; Williamson, L.E.; et al. Renewables 2014 Global Status Report 2014; INIS-FR-15-0638; INIS: Vienna, Austria, 2014.

3. KEMCO_Korea Energy Management Corporation. New \& Renewable Energy 2014 White Paper; KEMCO: Yongin, Korea, 2015.

4. Bhattacharyya, S.; Timilsina, G. A review of energy system models. Int. J. Energy Sect. Manag. 2010, 4, 494-518. [CrossRef]

5. Moura, P.S.; de Almeida, A.T. Multi-objective optimization of a mixed renewable system with demand-side management. Renew. Sustain. Energy Rev. 2010, 14, 1461-1468. [CrossRef]

6. Moreira, A.; Pozo, D.; Street, A.; Sauma, E. Reliable Renewable Generation and Transmission Expansion Planning: Co-Optimizing System's Resources for Meeting Renewable Targets. IEEE Trans. Power Syst. 2017, 32, 3246-3257. [CrossRef]

7. Zhang, N.; Hu, Z.; Springer, C.; Li, Y.; Shen, B. A bi-level integrated generation-transmission planning model incorporating the impacts of demand response by operation simulation. Energy Convers. Manag. 2016, 123, 84-94. [CrossRef]

8. Zolfaghari, S.; Akbari, T. Bilevel transmission expansion planning using second-order cone programming considering wind investment. Energy 2018, 154, 455-465. [CrossRef]

9. Menegaki, A. Valuation for renewable energy: A comparative review. Renew. Sustain. Energy Rev. 2008, 12, 2422-2437. [CrossRef]

10. Martínez Ceseña, E.A.; Mutale, J.; Rivas-Dávalos, F. Real options theory applied to electricity generation projects: A review. Renew. Sustain. Energy Rev. 2013, 19, 573-581. [CrossRef]

11. Dagoumas, A.S.; Koltsaklis, N.E. Review of models for integrating renewable energy in the generation expansion planning. Appl. Energy 2019, 242, 1573-1587. [CrossRef]

12. Davis, G.A.; Owens, B. Optimizing the level of renewable electric R\&D expenditures using real options analysis. Energy Policy 2003, 31, 1589-1608.

13. Siddiqui, A.S.; Marnay, C.; Wiser, R.H. Real options valuation of US federal renewable energy research, development, demonstration, and deployment. Energy Policy 2007, 35, 265-279. [CrossRef]

14. Kumbaroğlu, G.; Madlener, R.; Demirel, M. A real options evaluation model for the diffusion prospects of new renewable power generation technologies. Energy Econ. 2008, 30, 1882-1908. [CrossRef]

15. Jang, Y.-S.; Lee, D.-J.; Oh, H.-S. Evaluation of new and renewable energy technologies in Korea using real options. Int. J. Energy Res. 2013, 37, 1645-1656. [CrossRef]

16. Kim, K.-T.; Lee, D.-J.; Park, S.-J. Evaluation of R\&D investments in wind power in Korea using real option. Renew. Sustain. Energy Rev. 2014, 40, 335-347.

17. Munoz, J.I.; Contreras, J.; Caamano, J.; Correia, P.F. Risk assessment of wind power generation project investments based on real options. In Proceedings of the 2009 IEEE Bucharest PowerTech, Bucharest, Romania, 9 October 2009; pp. 1-8.

18. Lee, S.-C. Using real option analysis for highly uncertain technology investments: The case of wind energy technology. Renew. Sustain. Energy Rev. 2011, 15, 4443-4450. [CrossRef]

19. Martínez-Ceseña, E.A.; Mutale, J. Application of an advanced real options approach for renewable energy generation projects planning. Renew. Sustain. Energy Rev. 2011, 15, 2087-2094. [CrossRef]

20. Kiriyama, E.; Suzuki, A. Use of Real Options in Nuclear Power Plant Valuation in the Presence of Uncertainty with CO2 Emission Credit. J. Nucl. Sci. Technol. 2004, 41, 756-764. [CrossRef] 
21. Szolgayova, J.; Fuss, S.; Obersteiner, M. Assessing the effects of CO2 price caps on electricity investments-A real options analysis. Energy Policy 2008, 36, 3974-3981. [CrossRef]

22. Fuss, S.; Szolgayova, J.; Obersteiner, M.; Gusti, M. Investment under market and climate policy uncertainty. Appl. Energy 2008, 85, 708-721. [CrossRef]

23. Park, T.; Kim, C.; Kim, H. A real option-based model to valuate CDM projects under uncertain energy policies for emission trading. Appl. Energy 2014, 131, 288-296. [CrossRef]

24. Sarkis, J.; Tamarkin, M. Real options analysis for renewable energy technologies in a GHG emissions trading environment. Emissions Trading 2008, 103-119. [CrossRef]

25. Cheng, H.M.K.; Hou, Y.; Wu, F.F. Wind power investment in thermal system and emissions reduction. In Proceedings of the IEEE PES General Meeting, Providence, RI, USA, 30 September 2010; pp. 1-8.

26. Lee, S.-C.; Shih, L.-H. Renewable energy policy evaluation using real option model—The case of Taiwan. Energy Econ. 2010, 32, S67-S78. [CrossRef]

27. Lee, D.-J.; Kim, K.T. Economic evaluation of renewable energy R\&D in the presence of carbon emission market: Real option approach. In Proceedings of the Lecture Notes in Engineering and Computer Science, San Fancisco, CA, USA, 18 October 2016; Volume 2226, pp. 815-820.

28. Korea Energy Agency (KEA). 2018 New \& Renewable Energy White paper; Korea Energy Agency: Yongin, Korea, 2018.

29. Korea Power Exchange (KPX) Electric Power Statistics Information System (EPSIS). Available online: http://epsis.kpx.or.kr/ (accessed on 31 January 2020).

30. Ministry of Knowledge Economy. The Sixth Basic Plan for Long Term Electricity Demand and Supply; Ministry of Knowledge Economy: Seoul, Korea, 2013.

31. Trigeorgis, L. Real options: Managerial flexibility and strategy in resource allocation; The MIT Press: Cambridge, MA, USA, 1996.

32. Bank, W.; Ecofys; Vivid Economics. State and Trends of Carbon Pricing 2016; World Bank: Washington, DC, USA, 2016.

(C) 2020 by the authors. Licensee MDPI, Basel, Switzerland. This article is an open access article distributed under the terms and conditions of the Creative Commons Attribution (CC BY) license (http://creativecommons.org/licenses/by/4.0/). 